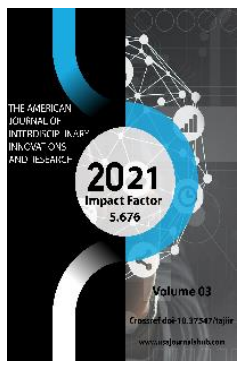

Copyright: Original content from this work may be used under the terms of the creative commons attributes 4.0 licence.

\section{Formation Of Socio-Economic Factors Affecting Traffic Safety}

\author{
Usmanova Mahira Nuralievna \\ Associate Professor Of The Department Of Engineering Of Intelligent Transport Systems, \\ Tashkent State Transport University, Tashkent, Uzbekistan \\ Rizaev Shuhratjon Shairovich \\ Assistant Professor Of The Department Of Transport Traffic Safety, MIA Academy Of The \\ Republic Of Uzbekistan, Tashkent, Uzbekistan
}

\title{
ABSTRACT
}

The article presents the results of a sociological study reflecting the problems of individual safety in the road traffic system. The assessment of the road safety of socio-economic factors is given. A sociological model of accidents and the stability of drivers is proposed.

\section{KEYWORDS}

Road safety, Road traffic accident, implementation of the transport process.

\section{INTRODUCTION}

Automobile transport as an integral element of the national economic complex of the country plays an important role in the implementation of the transport process. For the successful solution of the tasks set before the transport workers, it is necessary to further improve the transport system. Ensuring the safety of road transport is an integral part of the transport system. 
The mortality rates in road traffic accidents (RTA) in Uzbekistan per 100 thousand population are close to those of Canada (8), Australia (7) and France (7). The lowest death rate in road traffic accidents (4-6 people) in countries such as Israel, the Netherlands, Japan, Great Britain, Germany, Singapore, Sweden and Switzerland.

In the country in recent years, the problem of ensuring road safety (traffic safety) has been raised to the level of tasks state importance, several measures have been outlined and already implemented to reduce the accident rate and reduce the severity of the consequences of road accidents.

The modern level of the automotive process requires the organization of extensive research, the object of which is the main components of the VADS system. This complex is one of the functioning systems, i.e. is in dynamic mode.

The degree of OBTS in certain specific conditions is determined by the perfection and completeness of the mutual correspondence of the components of the VADS system $[(8,9,10,11,13]$, which is a generalized synthetic complex that depends on many sociological, technical, physiological and psychological factors affecting Road safety accident can be characterized as "mismatch" of the interaction of the links of the VADS system $[1,3,17,19]$.

Thus, to increase the effectiveness of measures to combat road accidents, it is necessary to determine the most capacious indicators and factors under the influence of which it is possible to exclude the causes of the accident $[2,3,5,6,11]$. The criteria for the approach to assessing the causes of accidents that exist so far are unambiguous - the driver is to blame. This is evidenced by data from foreign and domestic statistics of the causes of accidents about driver- $75 \%$, car- $15 \%$, road- $10 \%$.

The driver-control link of the named system, therefore, the OBD problem should be considered not only technical but also social $[13,14,15,16,17]$. We have mainly studied the socio-economic factors affecting traffic safety (DB). Among the socio-economic factors - the turnover of driver's personnel, affecting the state of traffic safety, the following are important:

- Social and demographic: age; marital status; education;

- General experience; length of service at the given enterprise;

- Social production: class; participation in the social life of the enterprise; correct use of working time;

- Social and economic: wage system; publicity in the system of material incentives;

- Social: living conditions; remoteness of housing from the place of work; cultural and social services; provision of children's institutions; organization of catering and sanitary services;

- Social and psychological: relationships in the team;

Relations with the administration; the prestige of the profession; job satisfaction.

To collect information, a methodology has been developed to study the impact of driver turnover based on the study of numerous works of domestic and foreign scientists in the field of traffic safety $[1,8,20]$, sociology and economics. This methodology allows us to identify the factors of accidents, to determine the portrait of drivers who quit the industry, to find out the degree of satisfaction of the needs of the driver's personnel from the auto enterprises.

\section{RESEARCH METHODS}

To identify the mass of factors, an integrated approach is required, which includes the following methods:

Methods for studying statistical accounting and reporting Methods for studying statistical 
accounting and reporting in practice are accepted to study the labour of personnel according to the data of primary accounting and reporting for several decades.

Interviewing - The collection of complete and high-quality information to analyze the reasons for the turnover of drivers and their work in the field of traffic safety is also carried out by interviewing, a completely acceptable method of socio-economic research for studying the work of each driver. The peculiarities of this interview method are that it is a lively and relaxed conversation between two people equally interested in it. Direct contact between the interviewer and the respondent creates many advantages for obtaining information that is inaccessible during the questionnaire survey.

Method of questionnaire survey - To collect more complete social information related to the turnover of drivers in vehicles, as in other sectors of the national economy, it is necessary to use special questionnaires that allow you to obtain a variety of information. The questionnaire also includes questions defining the work on the database. As a result of studying various forms of specialist questionnaires [1], we have developed special questionnaires for drivers and workers of motor transport enterprises.

Taking into account the experience of researching specialists for a quantitative assessment of the accident rate and stability of personnel drivers, depending on various socioeconomic factors, a multivariate model of correlation-regression analysis was selected.

In mathematical form, it can be written as follows:

$$
\bar{Y}=F\left(x_{1}, x_{2}, x_{3}, \ldots, x_{n}\right)
$$

Where, $\quad \bar{Y}$-dependent variable; $x_{n}-$ independent variables.
RTAs occur in the context of technical, socioeconomic factors $[1,13,17,18,19,20,21]$. In this case, the most important is the selection of influencing factors. So, one of the main conditions of factorial models is considered to be the elimination of factors that have a reverse and a direct relationship between themselves. When modelling the accident rate, it is necessary to pay attention to the factors that have the least connection with the function.

For the selection of factors, a model was first developed with all previously selected factors, and then gradually each of these factors was excluded from the structure of the model. The threshold for selection is 0.8 , that is, if the correlation value is greater than 0.8 (approaching -+1 ), then this indicates the presence of multicollinearity in the regression equation. The elimination of multicollinearity is carried out until a sharp decrease in the value of the coefficient of determination occurs.

As a result of the analysis for the bus fleet, the following factors were selected as the effective indicator and factor arguments:

$\mathrm{Y}_{1}$ - number of accidents, units; $X_{1}$ - frame stability,\%; $X_{2}$ - accident rate per 100 drivers, units; $X_{3}$ - violation of traffic rules, units; $X_{4}$ violation of labour discipline, units; $X_{5}$ - total number of drivers, people.; $X_{6}$ operating mode, hour; $X_{7}$ - participation of drivers in the public life of the enterprise, $\% X_{8}$; - participation of drivers in a DB class, $\% X_{9}$ - Percentage of drivers' medical examination coverage, $\% ; X_{10}$ fleet utilization rate; $X_{11}$ - technical readiness ratio; $X_{12}$ - the average number of vehicles, units; $X_{13}$ - production of one passengerkilometre, pass-km; $X_{14}$ - volume in income, USD.; $X_{15}$ - wage fund, USD.; $X_{16}$ - production of one driver, USD.; $X_{17}$ - average driver's wage, USD.; $X_{18}$ - dismissed for violation of traffic rules, people.

The same factors-arguments were chosen to study the dependence of the sustainability of 
personnel on the technical and economic indicators for the bus fleet.

For the development of sociological models for the object, as a result of careful analysis, the following factors were selected: $Y_{1}$ - accident rate during work, times; $Y_{2^{-}}$turnover of enterprises by drivers, times; $X_{1}$-sustainability of drivers' personnel, times; $X_{2}$ - total salary, USD; $X_{3}$ - organization of work, score; $X_{4}$-work experience at this enterprise, years; $X_{5^{-}}$ satisfaction with working conditions; $X_{6}$ average monthly salary, USD; $X_{7^{-}}$class of drivers; $X_{8^{-}}$grow up, years; $X_{9^{-}}$general experience, years;

1-table. Probabilistic and statistical indicators of the adequacy of the regression equation for accidents in the bus fleet

\begin{tabular}{|c|c|c|c|c|c|}
\hline \multirow[b]{2}{*}{ Contact form } & \multicolumn{3}{|c|}{ Coefficient } & \multicolumn{2}{|c|}{$\begin{array}{l}\text { The values } \\
\text { F- criteria }\end{array}$} \\
\hline & $\begin{array}{c}\text { Multiple } \\
\text { corr. R }\end{array}$ & $\begin{array}{c}\text { Cumulative } \\
\text { determination, } \\
\boldsymbol{R}^{\mathbf{2}}\end{array}$ & $\begin{array}{l}\text { Approximations, } \\
\boldsymbol{\varepsilon}\end{array}$ & $\begin{array}{l}\text { Table. } \\
\mathrm{P}=0.95\end{array}$ & $\begin{array}{c}\text { F } \\
\text { calculation }\end{array}$ \\
\hline Rectilinear & 0,84 & 0,7056 & 13,86 & 24 & 27,28 \\
\hline Logarithmic & 0.86 & 0,7396 & 14,37 & 24 & 25,68 \\
\hline Hyperbolic & 0,89 & 0,7744 & 14,85 & 24 & 27,82 \\
\hline Parabolic & 0,91 & 0,8281 & 15,00 & 24 & 48,27 \\
\hline In series & 0,89 & 0,7744 & 14,85 & 24 & 45,36 \\
\hline Inverse to straight & 0,89 & 0,7744 & 14,85 & 24 & 45,36 \\
\hline Inverse to logarithmic & 0,83 & 0,6889 & 12,64 & 24 & 37,75 \\
\hline Inverse to hyperbolic & 0,86 & 0,7921 & 14,63 & 24 & 29,67 \\
\hline Inverse to parabolic & 0,88 & 0,7744 & 14,77 & 24 & 30,25 \\
\hline Inverse to power law & 0,84 & 0,7056 & 13,86 & 24 & 25,96 \\
\hline
\end{tabular}

Taking into account the above factors, the models obtained the results for the objects. As a result of solving on a computer for eight models, the arithmetic mean values for each factor were determined $\bar{X}_{i}$, their standard deviations, coefficients of variation, F- Fisher's criterion and $t$ - Student criterion, pair correlation coefficients $r_{i},(R-$ multiple correlation coefficient), multiple determination coefficients $R^{2}$, etc... 
2-table. Probabilistic and statistical indicators of the adequacy of the regression equation for the stability of personnel in the bus fleet

\begin{tabular}{|c|c|c|c|c|c|}
\hline \multirow[b]{2}{*}{ Contact form } & \multicolumn{3}{|c|}{ Coefficient } & \multicolumn{2}{|c|}{$\begin{array}{l}\text { The values } \\
\text { F-criteria }\end{array}$} \\
\hline & $\begin{array}{c}\text { Multiple } \\
\text { corr. R }\end{array}$ & $\begin{array}{c}\text { Cumulative } \\
\text { determinations } \\
\boldsymbol{R}^{\mathbf{2}}\end{array}$ & $\begin{array}{c}\text { Approximations } \\
\boldsymbol{\varepsilon}\end{array}$ & $\begin{array}{c}\text { Tabl. } \\
\mathrm{P}=0.95\end{array}$ & $\begin{array}{c}F \\
\text { calculation }\end{array}$ \\
\hline Rectilinear & 0,83 & 0,6889 & 12,01 & 24 & 22,11 \\
\hline Logarithmic & 0.89 & 0,7921 & 14,09 & 24 & 40,76 \\
\hline Hyperbolic & 0,85 & 0,7921 & 14,09 & 24 & 35,97 \\
\hline Parabolic & 0,83 & 0,7744 & 12,00 & 24 & 39,21 \\
\hline In series & 0,85 & 0,7921 & 14,90 & 24 & 35,97 \\
\hline Inverse to straight & 0,86 & 0,7396 & 14,98 & 24 & 37,58 \\
\hline $\begin{array}{l}\text { Inverse to } \\
\text { logarithmic }\end{array}$ & 0,83 & 0,6889 & 12,01 & 24 & 22,09 \\
\hline $\begin{array}{l}\text { Inverse to } \\
\text { hyperbolic }\end{array}$ & 0,86 & 0,7396 & 14,98 & 24 & 37,85 \\
\hline $\begin{array}{l}\text { Inverse to } \\
\text { parabolic }\end{array}$ & 0,87 & 0,7569 & 15,00 & 24 & 38,67 \\
\hline $\begin{array}{l}\text { Inverse to power } \\
\text { law }\end{array}$ & 0,84 & 0,7056 & 13,63 & 24 & 25,96 \\
\hline
\end{tabular}

3-table. Probabilistic and statistical indicators of the adequacy of the regression equation for the accident rate of drivers according to the sociological model of the bus fleet

\begin{tabular}{|c|c|c|c|c|c|}
\hline \multirow[b]{2}{*}{ Contact form } & \multicolumn{3}{|c|}{ coefficient } & \multicolumn{2}{|c|}{$\begin{array}{l}\text { The values } \\
\text { F-criteria }\end{array}$} \\
\hline & $\begin{array}{l}\text { Multiple } \\
\text { corr. R }\end{array}$ & $\begin{array}{c}\text { Cumulative } \\
\text { determinations } \\
\boldsymbol{R}^{\mathbf{2}}\end{array}$ & $\begin{array}{c}\text { Approximations } \\
\boldsymbol{\varepsilon}\end{array}$ & $\begin{array}{c}\text { Tabl. } \\
\text { P=0.95 }\end{array}$ & $\begin{array}{c}\text { F } \\
\text { calculation }\end{array}$ \\
\hline Rectilinear & 0,79 & 0,6241 & 21,37 & 24 & 30,01 \\
\hline Logarithmic & 0.80 & 0,6400 & 19,85 & 24 & 32,97 \\
\hline
\end{tabular}


The American Journal of Interdisciplinary Innovations and Research (ISSN-2642-7478)

Published: April 22, 2021 | Pages: 28-35

Doi: https://doi.org/10.37547/tajiir/Volume03Issue04-05

\begin{tabular}{|c|c|c|c|c|c|}
\hline Hyperbolic & 0,83 & 0,6889 & 19,25 & 24 & 34,25 \\
\hline Parabolic & 0,87 & 0,7569 & 12,90 & 24 & 35,96 \\
\hline in series & 0,93 & 0,8649 & 12,00 & 24 & 38,97 \\
\hline $\begin{array}{c}\text { Back to } \\
\text { straight }\end{array}$ & 0,81 & 0,6561 & 14,03 & 24 & 29,85 \\
\hline $\begin{array}{c}\text { Inverse to } \\
\text { logarithmic }\end{array}$ & 0,83 & 0,6889 & 16,86 & 24 & 34,25 \\
\hline $\begin{array}{c}\text { Inverse to } \\
\text { hyperbolic }\end{array}$ & 0,85 & 0,7225 & 15,23 & 24 & 35,04 \\
\hline $\begin{array}{c}\text { Inverse to } \\
\text { parabolic }\end{array}$ & 0,87 & 0,7569 & 17,88 & 24 & 35,96 \\
\hline $\begin{array}{c}\text { Inverse to } \\
\text { power law }\end{array}$ & 0,89 & 0,7921 & 16,38 & 24 & 37,23 \\
\hline
\end{tabular}

\section{RESULTS AND DISCUSSIONS}

The selected form of communication, which most adequately writes off the studied one, from the analysis of the above tables, it can be seen that the largest multiple correlation coefficient in the parabolic form of communication for the model of accident rate of bus fleets is equal to $R=0.91$, for models of frame stability for the object $R=0.89$, and for sociological models for accidents during work power-law $R=0.93$, for the sustainability of personnel - a hyperbolic form of communication $=0.90$.

Fisher's tests were used to check the adequacy and compare the regression equations. When comparing the calculated values of Fisher's coefficients $\mathrm{F}$ at Nm-1, the degrees of freedom (where $\mathrm{N}$ is the number of observations, $\mathrm{m}$ is the number of factors in the model) were compared with the tabular values of Ftabl. The calculated $\mathrm{F}$-criteria for models of bus fleets in a parabolic form of connection for bus fleets is 48,27 ; in the logarithmic form of communication-40.76; for sociological models: accident rate-39.46; frame sustainability 37.64 .
Thus, the values of Fisher's criteria at a significance level of $P=0.05$ do not contradict the hypothesis about the presence of the selected forms of communication, since for all models Fcal> Ftabl

The significance of the regression coefficients was tested using the Student's t-test at the same degrees of freedom.

\section{CONCLUSIONS}

To assess the quantitative influence of factors on the accident rate (Road traffic accident), the pattern recognition method was used. At the same time, information weights are determined, the degree of importance of each studied factor, which are grouped taking into account the homogeneity and proximity to each other. The analysis of all groups made it possible to objectively assess and take into account the real possibilities and reserves of managing these factors. 


\section{REFERENCES}

1. Usmanova M.N. (1991). Mathematical and statistical modelling of road safety processes. Dissertation for the degree of candidate of economic sciences.

2. Usmanova M.N. (2017). Determination of priority directions of activity of the road safety service at the automobile transport enterprises. TADI Bulletin. Scientific and technical journal. 3(4). 102-106 pp.

3. Usmanova M.N. (2016). An approach to assessing driver skills factors in traffic safety. Bulletin of TADI. Scientific and technical journal. 4. 90-93 pp.

4. Usmanova M.N. (2019). Directions of traffic organization in large cities. Business Expert. (8), 42-44p.

5. Slesarchuk, S. V. (2019). Analysis of the causes of road traffic accidents involving young drivers. Young scientist. 20(258). pp. 360-361.

URL: https://moluch.ru/archive/258/59169/(date of access: 24.02.2021

6. R. Abdulzyanov Sociology of a region http://regionsar.ru ISSN 2413-1407, eISSN 2587-8549 Factors affecting road safety in the region

7. World Health Organization, Global status report on road safety 2015 (Geneva, 2015).

8. Penshin N.V.1, Ivlev V.Y.21 PhD in Economics, 2 undergraduate, department of «Organization of transportations and safety of travelling motion», Tambov State Technical University

9. Lu, M., Wevers, K., \& Bekiaris, E. (2006, October). Traffic safety principles and physical road infrastructure measures. In Presentation at the 19th ICTCT (International Cooperation on Theories and Concepts in Traffic safety) Workshop, Minsk.

10. Li, X., Wu, L., \& Yang, X. (2018). Exploring the impact of social economic variables on traffic safety performance in Hong Kong: $A$ time series analysis. Safety science, 109, 6775.
11. Whitlock, G., Norton, R., Clark, T., Pledger, M., Jackson, R., \& MacMahon, S. (2003). Motor vehicle driver injury and socioeconomic status: a cohort study with prospective and retrospective driver injuries. Journal of Epidemiology \& Community Health, 57(7), 512-516.

12. Sun, L. L., Liu, D., Chen, T., \& He, M. T. (2019). Road traffic safety: An analysis of the cross-effects of economic, road and population factors. Chinese journal of traumatology, 22(5), 290-295.

13. Heydari, S., Hickford, A., Mcllroy, R., Turner, J., \& Bachani, A. M. (2019). Road safety in low-income countries: state of knowledge and future directions. Sustainability, 11(22), 6249.

14. Haghighi, M. R. R., Sayari, M., Ghahramani, S., \& Lankarani, K. B. (2020). Social, economic, and legislative factors and global road traffic fatalities. BMC public health, 20(1), 1-12.

15. Anciaes, P. R., Metcalfe, P. J., \& Heywood, C. (2017). Social impacts of road traffic: Perceptions and priorities of local residents. Impact assessment and project appraisal, 35(2), 172-183.

16. Machado-León, J. L., de Oña, J., de Oña, R., Eboli, L., \& Mazzulla, G. (2016). Socioeconomic and driving experience factors affecting drivers' perceptions of traffic crash risk. Transportation research part F: traffic psychology and behaviour, 37, 41-51.

17. Atombo, C., Wu, C., Tettehfio, E. O., \& Agbo, A. A. (2017). Personality, socioeconomic status, attitude, intention and risky driving behavior. Cogent Psychology, 4(1), 1376424., https://doi.org/10.1080/23311908.2017.1376 424

18. Krüger, N. A. (2013). Fatal connectionssocioeconomic determinants of road accident risk and drunk driving in Sweden. Journal of safety research, 46, 59-65. https://doi.org/10.17265/1548-

7709/2016.03.006 
19. Payani, S., Hamid, H., \& Law, T. H. (2019, November). A review on impact of human factors on road safety with special focus on hazard perception and risk-taking among young drivers. In IOP Conference Series: Earth and Environmental Science (Vol. 357, No. 1, p. 012041). IOP Publishing.

20. Petridou, E., \& Moustaki, M. (2000). Human factors in the causation of road traffic crashes. European journal of epidemiology, 16(9), 819-826.

21. Alavi, S. S., Mohammadi, M. R., Soori, H., \& Ghanizadeh, M. (2017). The cognitive and psychological factors (personality, driving behavior, and mental illnesses) as predictors in traffic violations. Iranian journal of psychiatry, 12(2), 78. 